Article

\title{
Chitosan-ZnO Nanocomposites Assessed by Dielectric, Mechanical, and Piezoelectric Properties
}

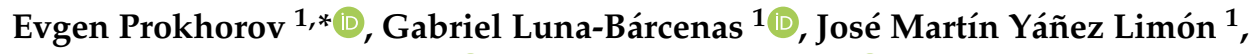 \\ Alejandro Gómez Sánchez ${ }^{1}$ (D) and Yuriy Kovalenko ${ }^{2} \mathbb{D}$ \\ 1 Cinvestav, Unidad Querétaro, Querétaro 76230, QRO, Mexico; gabriel.luna@cinvestav.mx (G.L.-B.); \\ jmyanez@cinvestav.mx (J.M.Y.L.); alejandrogomez@cinvestav.mx (A.G.S.) \\ 2 Postgraduate Department, University of Aeronautics of Querétaro, Querétaro 76278, QRO, Mexico; \\ kovalenko.yuriy@gmail.com \\ * Correspondence: prokhorov@cinvestav.mx
}

Received: 28 July 2020; Accepted: 28 August 2020; Published: 1 September 2020

\begin{abstract}
The aim of this work is to structurally characterize chitosan-zinc oxide nanoparticles (CS-ZnO NPs) films in a wide range of NPs concentration (0-20 wt.\%). Dielectric, conductivity, mechanical, and piezoelectric properties are assessed by using thermogravimetry, FTIR, XRD, mechanical, and dielectric spectroscopy measurements. These analyses reveal that the dielectric constant, Young's modulus, and piezoelectric constant $\left(\mathrm{d}_{33}\right)$ exhibit a strong dependence on nanoparticle concentration such that maximum values of referred properties are obtained at $15 \mathrm{wt} . \%$ of $\mathrm{ZnO}$ NPs. The piezoelectric coefficient $\mathrm{d}_{33}$ in CS-ZnO nanocomposite films with $15 \mathrm{wt} . \%$ of NPs $\left(\mathrm{d}_{33}=65.9 \mathrm{pC} / \mathrm{N}\right)$ is higher than most of polymer-ZnO nanocomposites because of the synergistic effect of piezoelectricity of NPs, elastic properties of CS, and optimum NPs concentration. A three-phase model is used to include the chitosan matrix, ZnO NPs, and interfacial layer with dielectric constant higher than that of neat chitosan and $\mathrm{ZnO}$. This layer between nanoparticles and matrix is due to strong interactions between chitosan's side groups with ZnO NPs. The understanding of nanoscale properties of CS-ZnO nanocomposites is important in the development of biocompatible sensors, actuators, nanogenerators for flexible electronics and biomedical applications.
\end{abstract}

Keywords: chitosan; zinc oxide nanoparticles; interfacial layer; dielectric spectroscopy

\section{Introduction}

Zinc oxide nanoparticles (ZnO-NPs) are one of the most attractive materials due to their unique optical, piezoelectric, mechanical, and antibacterial properties. Nanocomposites based upon ZnO-NPs are widely used for the development of different optoelectronic, electronic, sensors, collar cells, etc., devices (see, for example [1-3]). Recently, there were published significant publications about the potential use of ZnO-NPs that include flexible devices such as supercapacitance [4], flexible piezoelectric nanogenerators with ZnO-polyvinylidene fluoride (PVDF) [5,6], piezoelectric vibration sensors based on polydimethylsiloxane (PDMS) and $\mathrm{ZnO}$ nanoparticle [7], soft thermoplastic material with polyurethane matrix [8], poly (ethylene oxide) and poly (vinyl pyrrolidone) blend matrix incorporated with zinc oxide $(\mathrm{ZnO})$ nanoparticles for optoelectronic and microelectronic devices [9], gate transistors with $\mathrm{ZnO}$ and ethyl cellulose [10], chitosan- $\mathrm{ZnO}$ (CS-ZnO) nanocomposite for packing applications [11-13], CS-ZnO as antibacterial agent [13-15], and CS-ZnO nanocomposite for supercapacitor [16].

Based upon the above information, chitosan-based nanocomposites offer significant scientific and technological potential. In this regard, chitosan (CS), a polysaccharide obtained from the deacetylation of chitin, is a natural polymer with high absorption capacity, biodegradability, biocompatibility with antibacterial features. Additionally, chitosan is a hydrophilic polymer with $\mathrm{NH}_{2}$ and $\mathrm{OH}$ side 
groups which can interact with $\mathrm{ZnO}$ nanoparticles via hydrogen bonding and form nanocomposites with new properties [17-19]. It is noteworthy that the literature reports publications that deal with different methods of CS-ZnO nanocomposite preparation and their antibacterial, optical, photocatalytic activity (see, for example [11-20]), and mechanical [15,21-23] properties. In the case of mechanical properties, it has been reported that the $\mathrm{ZnO}$ content improves mechanical properties not only in CS-ZnO composite [15,22,23] but also in CS-cellulose-ZnO [24] and in CS-PVA-ZnO [25] materials.

However, to the best our knowledge, the literature does not properly address the influence of $\mathrm{ZnO}$ content on the conductivity of CS-ZnO nanocomposite; in this regard there are two controversial articles related to the effect of $\mathrm{ZnO}$ additional on the dielectric constant of CS-ZnO membranes (in [23] with additional of ZnO NPs dielectric constant increase and in [26] decrease). The conductivity and dielectric properties play important role in applications of CS-ZnO nanocomposites in flexible organic electronics in a wide range of devices like transistors, sensors, flexible piezoelectric nanogenerators, ultraviolet photodetectors, photodiodes, etc., [4,23].

One of the most important questions related not only for application of CS-ZnO nanocomposites but also for all nanotechnology is how to find the best/optimum concentration of NPs with the best performance for different applications. CS-ZnO membrane composites consist of dielectric CS matrix and $\mathrm{ZnO}$ semiconductor fillers with wide bandgap with static dielectric constant ca. 8.5 [27] and low conductivity (ca. $10^{-4}-10^{-5} \mathrm{~S} / \mathrm{cm}$, which depends upon intrinsic defects created by oxygen vacancies [28-30]). Therefore, this material can be considered as a dielectric matrix with dielectric inclusions. It is noteworthy that for different polymer-ZnO NPs composites, the dielectric constant depends upon $\mathrm{ZnO}$ content where a maximum is observed; for instance, in PVDF-ZnO at 0.06 vol.\% of $\mathrm{ZnO}$ [31]; in PVDF-ZnO 5.5 vol.\% of $\mathrm{ZnO}$ [32]; in PVDF-ZnO at $15 \mathrm{wt} . \%$ [33]: in PVA/PVP-ZnO at $8 \mathrm{wt} . \%$ [34]; in PVA-ZnO at $10 \mathrm{~mol} \%$ [35]. The explanation of the maximum in the dielectric constant proposed in these articles is based upon classical percolation theory; by increasing conductivity inclusions in dielectric matrix the conductivity of composites increases at the percolation threshold and upon higher concentration of fillers there appears a saturation. The dielectric constant also shows a maximum near the percolation threshold [36,37]; however, refs. [31-35] do not report a conductivity percolation effect. It is noteworthy that ZnO NPs exhibit low conductivity such that the PVA-ZnO composite's conductivity is ca. $10^{-7}-10^{-9} \mathrm{~S} / \mathrm{cm}$ [35] and PVA/PVP-ZnO is less than $10^{-7} \mathrm{~S} / \mathrm{cm}$ [34]. Therefore, such material cannot exhibit conductivity percolation phenomena and this model cannot be used to explain the maximum in dielectric constant.

Similarly, to the dielectric behavior, there is a maximum on the Young's modulus as a function of $\mathrm{ZnO}$ concentration. Ref. [38] reports a maximum on the Young's modulus in PHBV-ZnO (Poly(3-hydroxybutyrate-co-3-hydroxyvalerate-ZnO) at a composition of $4 \mathrm{wt}$.\% of NPs; Ref. [39] reports that system PEEK-ZnO (poly(ether ether ketone)-ZnO) shows a maximum at $5 \mathrm{wt} . \%$ of $\mathrm{ZnO}$; PMMA-ZnO at $1 \mathrm{wt} . \%$ of NPs [40]; PLA-ZnO at $2 \mathrm{wt} . \%$ [41]. In summary, such a maximum in Young's modulus has been related to the distribution of nanoparticles within the polymer matrix and strong interfacial adhesion that can enhance the mechanical properties of nanocomposites [42].

In general, in polymer-ZnO NPs composites both dielectric constant and Young's modulus share a common feature: by increasing NPs concentration both properties increase [43,44]. Consequently, it is conceivable that dielectric, mechanical, and piezoelectric properties can be optimized by varying the concentration of $\mathrm{ZnO}$ NPs in chitosan nanocomposites for different applications.

Based upon the above discussion, this work aims to investigate the structural properties of CS-ZnO films including their dielectric, conductivity, mechanical and piezoelectric properties by varying the concentration of $\mathrm{ZnO}$ nanoparticles. To assess this study, we take advantage of impedance spectroscopy, FTIR, XRD, thermogravimetry, and piezoelectric measurements. 


\section{Materials and Methods}

Chitosan (CS, medium molecular weight, deacetylation ca. 72\%), acetic acid (99.7\%), and $\mathrm{ZnO}$ NPs dispersed in water (20 wt.\% in water) with dimension ca. $40 \mathrm{~nm}$ were purchased from Sigma Aldrich (St. Louis, MO, USA) and used as received.

CS solution (1 wt.\%) was prepared in acetic acid solution (1 vol.\%) and stirred for $24 \mathrm{~h}$. Different amounts of $\mathrm{ZnO}$ sonicate colloidal solutions with various weight percent of $\mathrm{ZnO}(5,10,15$, and $20 \mathrm{wt} . \%$ with respect to CS dry-base) were dispersed in the CS solution by ultrasound for $30 \mathrm{~min}$ at $60 \mathrm{~Hz}$. Finally, $18 \mathrm{~mL}$ of each nanocomposite solutions were placed in Petri dishes and dried during $20 \mathrm{~h}$ at $60{ }^{\circ} \mathrm{C}$ to obtain films with thickness ca. $40 \mu \mathrm{m}$. For impedance measurements, CS-ZnO films were gold-sputtered on both sides to serve as contacts.

The amount of free water was determined by thermogravimetric analysis (TGA) (TGA 4000-PerkinElmer, Walham, MA, USA). Measurements were made in the dry air with a heating rate of $10^{\circ} \mathrm{C} / \mathrm{min}$. The interaction between CS functional groups with $\mathrm{ZnO}$ was analyzed by FTIR measurements on a Perkin Elmer Spectrum GX spectrophotometer using ATR (MIRacle ${ }^{\mathrm{TM}}$ ) sampling technique, with a diamond tip, in the range from 4000 to $650 \mathrm{~cm}^{-1}$ at room temperature. The crystalline structure of $\mathrm{ZnO}$ and CS-ZnO films were tested by an X-ray diffractometer (Rigaku Dmax 2100, The Woodlands, TX, USA) with $\mathrm{Cu} K \alpha$ radiation $(\lambda=0.154 \mathrm{~nm})$.

Impedance measurements were carried out using Agilent $4249 \mathrm{~A}$ in the frequency range $40 \mathrm{~Hz}-100 \mathrm{MHz}$ with an amplitude of AC voltage $100 \mathrm{mV}$ at room temperature. DC resistance $R$ and capacitance $C$ at the limit of zero frequency were calculated from fitting impedance spectra using ZView program. Conductivity and static dielectric constant (at the limit of zero frequency) were calculated from the following relationship: $\sigma=d /(R \cdot S), \varepsilon=(C \cdot d) /\left(\varepsilon_{0} \cdot S\right)$, where $d$ and $S$ are the thickness and area of samples, respectively. Film thickness was measured in each sample using micrometer Mitutoyo with resolution $1 \mathrm{mkm}$. The mechanical test was performed on an Instron universal tensiometer material testing system (model TX2plus). Each composite film was cut with dimensions according to ASTM Standard D638-Epsilon. Each strip was held with a distance between clamps of $25 \mathrm{~mm}$. The test was performed with the lower grip was fixed, and the upper grip rose at an extension rate of $1 \mathrm{~mm} / \mathrm{sec}$ at room temperature. All the failures occurred in the middle region of the testing strips. This test was repeated six times for each specimen to confirm its repeatability.

The measurements of ferroelectric polarization loops (P versus E) and deformation curves as a function of the applied field (butterfly curves) were obtained simultaneously by placing the samples in a measuring cell with parallel electrodes immersed in silicone oil to avoid dielectric breakage of the surrounding medium with voltage step $100 \mathrm{~V}$ before sample breakdown. The polarization and deformation curves presented in this work correspond to the maximum applied voltage measured before film breakdown. The ferroelectric measurements were based on the principle of the Sawyer-Tower circuit using a Precision LC materials analyzer, Radiant Technologies Inc., coupled with a TREK Model 609E-6 voltage amplifier source. Results presented in this work correspond to the maximum voltage before the breakdown of the sample.

\section{Results}

XRD analysis can supply information about the crystalline structure of ZnO NPs and Cs-ZnO NPs films (Figure 1). XRD pattern of neat CS and CS-ZnO (with $20 \mathrm{wt} . \%$ of NPs) show the diffraction peak at $2 \theta \approx 24^{\circ}$ (hydrate crystalline phase, Form 1 ) and a weak peak at $2 \theta \approx 16.9^{\circ}$ (hydrate crystalline phase, Form 2) [45]. The peaks observed in ZnO NPs and CS-ZnO films were in good agreement with the database of hexagonal $\mathrm{ZnO}$ particles (JCPDS No. 36-1451) and the results are reported in refs. $[15,19,23]$. This means that structure of ZnO NPs was not modified by the presence of CS [18,20], but the intensity of broad CS peak at $2 \theta \approx 24^{\circ}$ decrease in CS-ZnO films indicated the increase in the degree of amorphous regions of the nanocomposites films due to the interaction between the CS matrix and $\mathrm{ZnO}$ NPs and decreasing of water content [25]. Measurements of CS-ZnO films were carried out 
on copper substrate; therefore, there are additional diffraction patterns associated to $\mathrm{Cu}$ substrate at $2 \theta$ $\approx 43.3^{\circ}$ and $2 \theta \approx 50.4^{\circ}$; this fact is indicated in Figure 1.

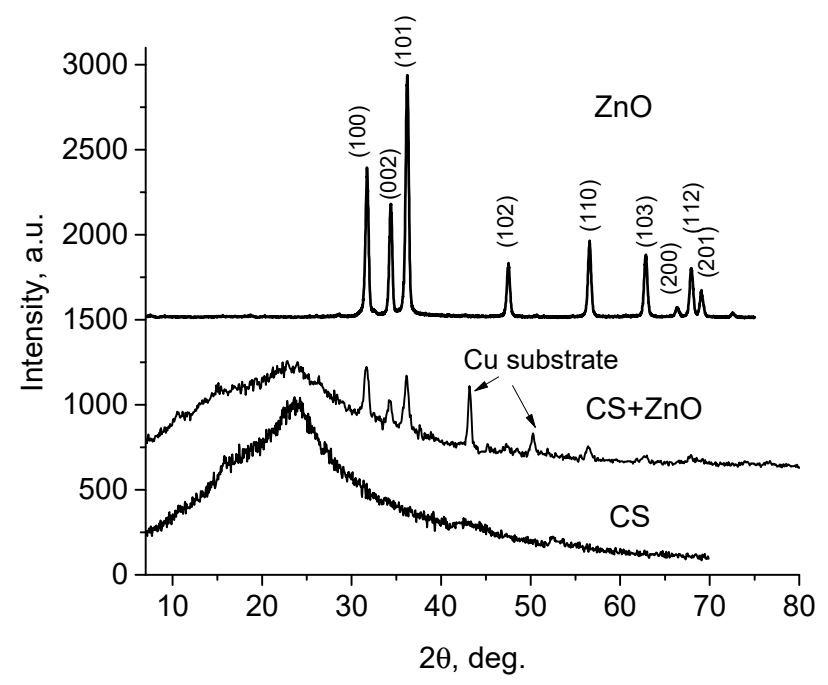

Figure 1. X-ray diffraction patterns of neat chitosan (CS) film, CS ZnO NPs composite, and ZnO nanoparticles (NPs).

The average size of particles $(D)$ was calculated using the Debye-Scherrer equation $[18,19]$ :

$$
D=k \lambda / \beta \cos \theta
$$

where the value of $k$ is equal to $0.89, \lambda$ is the wavelength of $X$-ray $(1.54 \circ \mathrm{A}), \beta$ is the full width at half maximum, and $\theta$ is the half of the diffraction angle. The average value of crystallites (calculated using three diffraction peaks (100), (002), and (101)) were $45.3 \mathrm{~nm}$ which correlates well with the dimension of NPs (ca. $40 \mathrm{~nm}$ ).

Figure 2 shows the FTIR spectra of neat CS films and CS-ZnO films with 10 and $20 \mathrm{wt} . \%$ of ZnO NPs. In the case of chitosan, the broadband characteristic peak centered at $3252 \mathrm{~cm}^{-1}$ corresponds to the overlap of stretching vibration of $-\mathrm{NH}$ and $-\mathrm{OH}$ groups shift in $\mathrm{CS}-\mathrm{ZnO}$ films to lower wavenumber at $3227 \mathrm{~cm}^{-1}$. The absorption peaks of CS at 1636 (amide I group), $1542 \mathrm{~cm}^{-1}$ (bending vibrations of $\mathrm{NH}_{3}$ ), and 1065 (the stretching vibration of $\mathrm{C}-\mathrm{O}-\mathrm{C}$ of the glycosidic linkage) in CS-ZnO films shift to lower wavenumber (Figure 2) due to the interaction of these group with $\mathrm{ZnO}$ and formation of a hydrogen bond between $\mathrm{ZnO}$ and chitosan. This result is in good agreement with previous reports $[15,18,19,23,46]$.

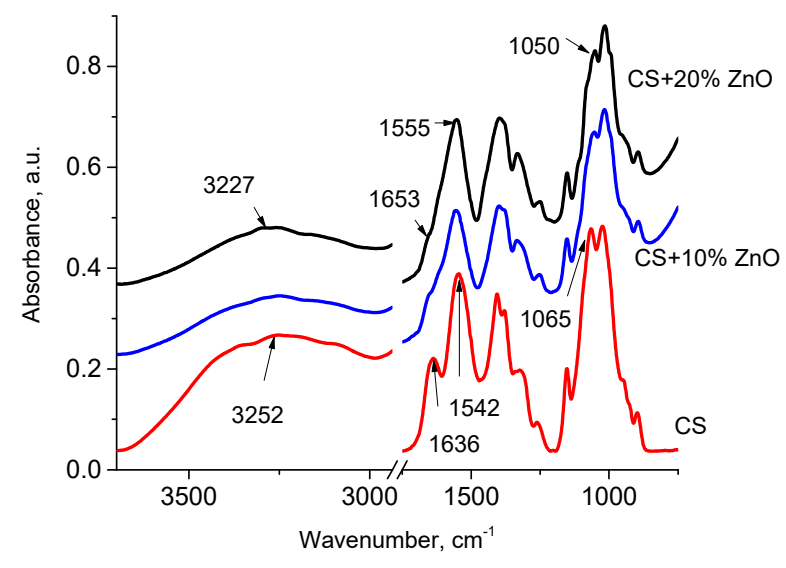

Figure 2. FTIR spectra of neat CS films and CS-ZnO films with 10 and $20 \mathrm{wt} . \%$ of ZnO. 
Another confirmation of strong interaction between side groups of CS with ZnO NPs can be obtained from TGA measurements (Figure 3). It was previously reported [47] that neat CS exhibits a two-step weight loss. From room temperature to ca. $150{ }^{\circ} \mathrm{C}$, the weight loss is related to the water evaporation and in the temperature range of $170-300{ }^{\circ} \mathrm{C}$, the weight loss is due to the degradation of the CS [47]. Water absorption in CS is closely linked to the availability of amino and hydroxyl groups of CS that interact via hydrogen bonding with water molecules $[47,48]$. It has been observed that the water content depends upon $\mathrm{ZnO} N$ Ps concentration (Figure 3) and it decreases with increasing weight $\%$ of NPs $(11.7 \%$ in neat CS and 7.3\% in CS-ZnO film with $20 \mathrm{wt} . \%$ of NPs, at the temperature $140{ }^{\circ} \mathrm{C}$ ). As it was shown by FTIR analysis, these groups can bond with ZnO NPs; therefore, a decrease in the water absorption ability with increasing $\mathrm{ZnO}$ concentration is observed.

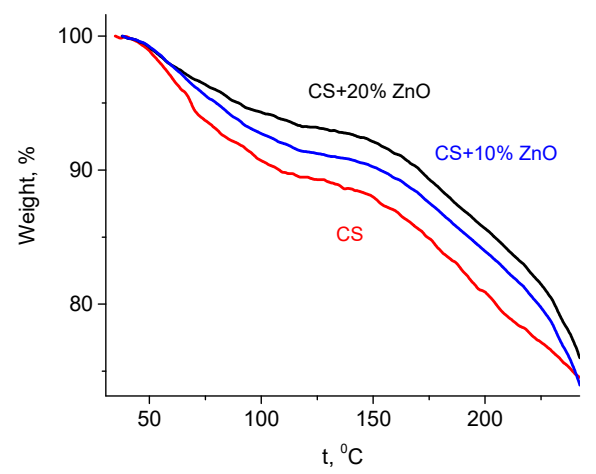

Figure 3. TGA measurements of pure CS and CS-ZnO NPs films with 10 and $20 \mathrm{wt} . \%$ of NPs.

The results obtained from XRD, FTIR, and TGA measurements have shown an interaction between CS matrix and ZnO NPs that play an important role in the explanation of electrical and mechanical properties of the nanocomposite.

Figure $4 \mathrm{a}$ shows the dependence of DC conductivity and Figure $4 \mathrm{~b}$ shows the dependencies of the dielectric constant in the limit of zero frequency as a function of ZnO NPs wt.\%. It is evident from Figure $4 \mathrm{~b}$ that dependence of dielectric constant exhibits a maximum at a concentration of $\mathrm{ZnO}$ NPs of ca. $15 \mathrm{wt} . \%$ and it is higher than the static dielectric constant of neat $\mathrm{ZnO}$ (ca. 8.5 [27]). It is noteworthy that the conductivity of CS- $\mathrm{ZnO}$ nanocomposite (Figure $4 \mathrm{a}$ ) is sufficiently lower than the $\mathrm{ZnO}$ conductivity $\left(\mathrm{ca} .1 \times 10^{-5} \mathrm{~S} / \mathrm{cm}[28,29]\right)$ and it decreases with $\mathrm{ZnO} N P s$ wt. $\%$.
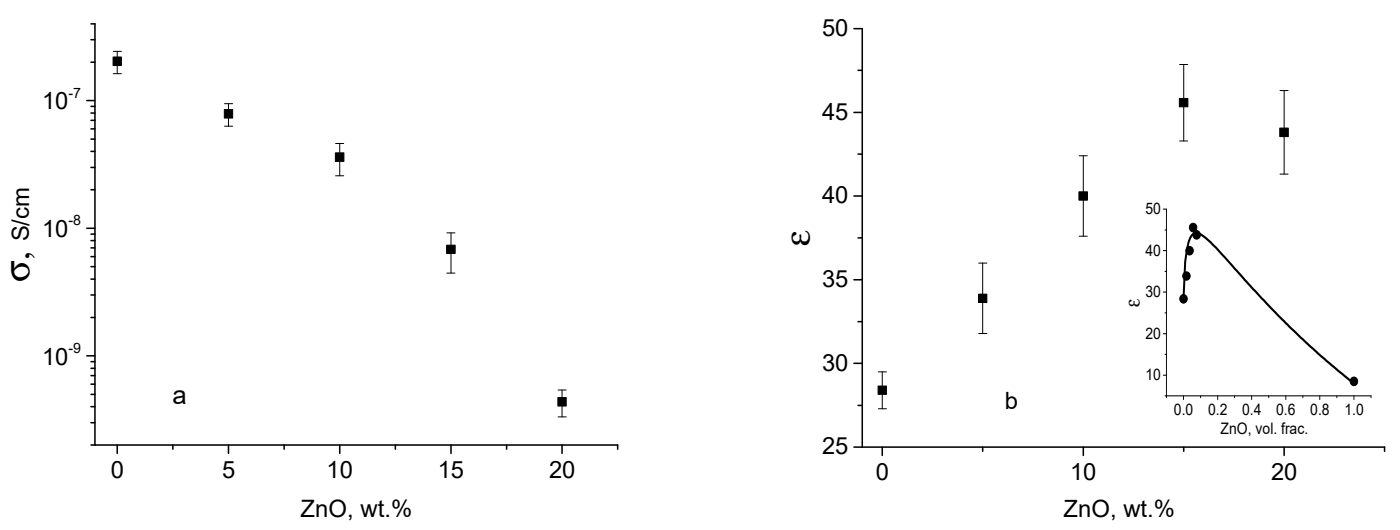

Figure 4. Dependences of (a) DC conductivity $(\sigma)$ and (b) dielectric constant $(\varepsilon)$ in the limit of zero frequency obtained in $\mathrm{CS}-\mathrm{ZnO}$ films with different $\mathrm{ZnO}$ concentration at room temperature. Insert in Figure $4 \mathrm{~b}$ shows dependence of $\varepsilon$ on the volume fraction of ZnO NPs: points-experimental measurements and continuous line-results of the fitting.

Similarly, to the dielectric constant behavior, there is maximum in the dependence of Young's modulus on $\mathrm{ZnO}$ wt.\% (Figure 5). Young's modulus increases from $1.7 \mathrm{GPa}$ (in neat CS) to 9.09 GPa 
in films with $15 \mathrm{wt} .=\%$ of NPs. At concentration of ZnO NPs $20 \mathrm{wt} \%$, Young's modulus decreases to $4.5 \mathrm{GPa}$. The increasing of Young's modulus with $\mathrm{ZnO}$ concentration has been previously reported $[12,15,20]$ and it has been interpreted by an additional energy-dissipating mechanism [12], weakness of intermolecular hydrogen bonds of CS formation of new hydrogen bonds between CS and $\mathrm{ZnO}$ [15]. CS-PVA-ZnO NPs membrane study [25] reported the maximum in Young's modulus at $10 \mathrm{wt} . \%$ of NPs which has been explained by the interaction of ZnO NPs with CS-PVA functional groups.

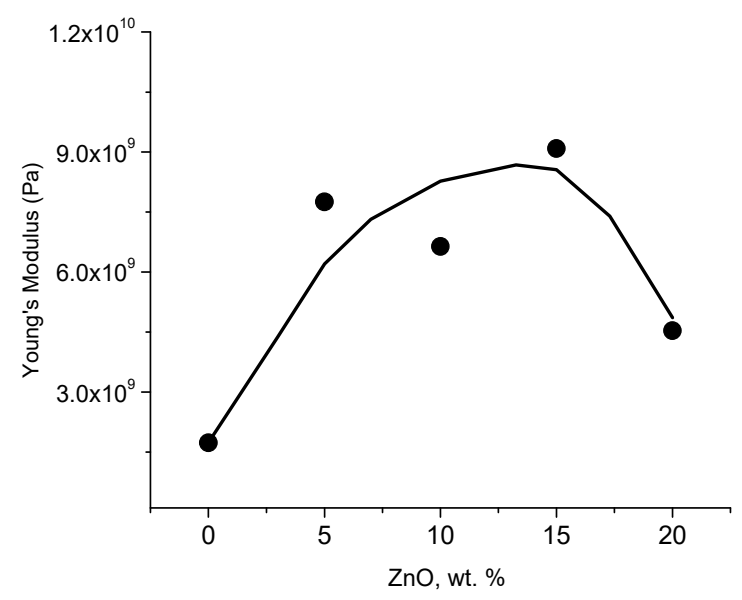

Figure 5. Dependence of Young's modulus of CS ZnO NPs films with different wt.\% of NPs (points). The continuous line is a guide to the eye.

$\mathrm{ZnO}$ is a well-known material that exhibits both ferroelectric and piezoelectric behavior. Therefore, it is important to investigate these properties in CS-ZnO nanocomposites which can find applications in flexible electronics.

Figure 6 shows the ferroelectric hysteresis curve obtained in the CS-ZnO NPs film with 15 and $20 \mathrm{wt} . \%$ of NPs. The shape of the curve is typical for samples with electrical leakage, which prevents reaching saturation in the polarization [49]. This leakage current can be associated with the intrinsic proton conductivity of the CS matrix [50]. The corresponding deformation curves do not present symmetrical shape, probably because of the interaction between $\mathrm{ZnO}$ NPs and CS. The piezoelectric coefficient $d_{33}$ was evaluated in the linear region of the deformation curve vs. applied voltages using the expression $\mathrm{d}_{33}=\Delta \mathrm{l} / \Delta \mathrm{V}[51,52]$. The piezoelectric coefficient $\mathrm{d}_{33}$ in CS-ZnO nanocomposite films with $15 \mathrm{wt} . \%$ of NPs $\left(\mathrm{d}_{33}=65.9 p \mathrm{C} / \mathrm{N}\right)$ is higher than in neat $\mathrm{ZnO} \mathrm{NPs}$ (between 0.4 and $12.4 p C / \mathrm{N}[53,54]$ ) and in poly(vinylidene fluoride) PVDF-ZnO flexible films (13.42 $p C / N$ [55], 18.3 $p C / N$ [56], $50 p C / N$ [52]) and compared with PVDF-PTTE-ZnO nanorods (70.3 $p C / N$ with 15 wt.\% of nanorods [57]). Note, that PVDF is a polymer with piezoelectric properties.
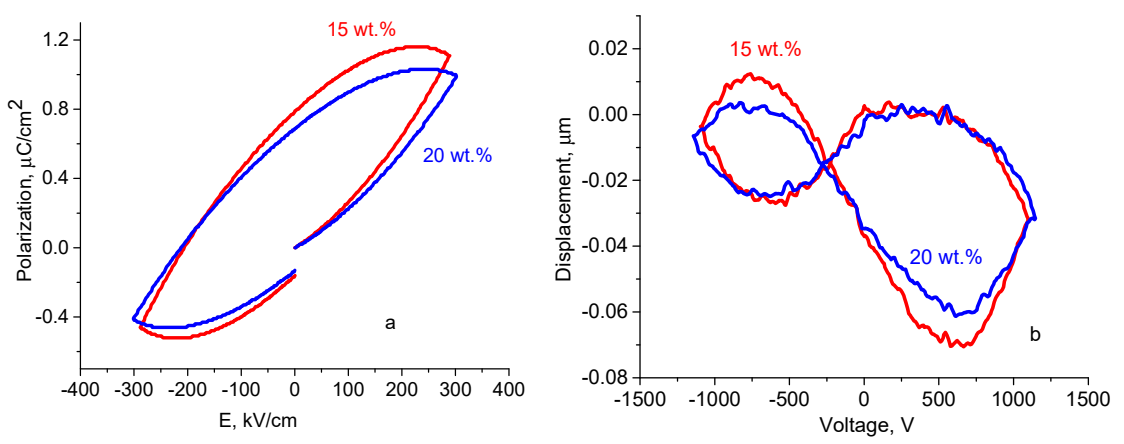

Figure 6. Ferroelectric hysteresis curve of (a) CS-ZnO NPs nanocomposites, (b) corresponding deformation curve $\Delta \mathrm{l}$ vs. $\mathrm{V}$ for CS-ZnO films with different wt.\% of NPs indicate on the graph. 
Such a high piezoelectric coefficient can be related to elastic properties of the CS matrix because the viscous and elastic properties play an important role in the piezoelectric performance of piezoelectric polymer composites [58].

Additionally, piezoelectric coefficient $d_{33}$ demonstrate higher value $\left(d_{33}=65.9 p C / N\right)$ in CS-ZnO films with 15 . wt. $\%$ of NPs than in films with $20 \mathrm{wt} . \%\left(\mathrm{~d}_{33}=60.6 \mathrm{pC} / \mathrm{N}\right)$.

\section{Discussion}

Bulk conductivity of $\mathrm{ZnO}$ is ca. $10^{-4}-10^{-5} \mathrm{~S} / \mathrm{cm}$ and it depends upon intrinsic defects created by oxygen vacancies [28-30]). Conductivity of nanoparticles depends upon grain size, morphology, and microstructure and it is ca. $1.5 \times 10^{-7} \mathrm{~S} / \mathrm{cm}$ [59]. Because of the low volume fraction of $\mathrm{ZnO}$ NPs in CS-ZnO films (from 0 to $0.15 \mathrm{wt} . \%$; see below the volume fraction calculation), the effective conductivity of nanocomposites practically depends upon the conductivity of neat CS $\left(\mathrm{ca} .10^{-7} \mathrm{~S} / \mathrm{cm}\right)$. The conductivity of neat CS is related to the Grotthuss mechanism in which the protons are originated from the protonated amino groups that can move along the hydrated molecule in the hydrogen-bonding network via hopping process [50]. Because of the strong interaction of reactive CS side groups with $\mathrm{ZnO}$ NPs (as probed by FTIR measurements) the number of generated protons and the number of hydrated molecules decrease (TGA measurements); this plausible scenario is responsible for the decreasing of nanocomposite's conductivity.

As a rule, the effective dielectric constant $\varepsilon$ and conductivity $\sigma$ of a mixture of two materials with different $\varepsilon$ and $\sigma$ can be calculated using models as the Maxwell, Bruggeman, Lichtenecker, or different percolation model [60-62]. However, all these models produce a monotonic decreasing of the effective dielectric constant with increasing concentration of nanoparticles in the polymer (because $\varepsilon$ of CS films is ca. 25 and $\varepsilon$ of $\mathrm{ZnO}$ is ca. 8.5 [27]); it also can show a monotonic increasing of effective conductivity with increasing concentration of (because $\sigma$ of CS is ca. $2 \times 10^{-7} \mathrm{~S} / \mathrm{cm}$ and $\sigma$ of $\mathrm{ZnO}$ is ca. $10^{-4}-10^{-5} \mathrm{~S} / \mathrm{cm}$ ).

In contrast to those models, refs. [63,64] proposed a three-phase model to describe the dielectric properties of polymer-ceramic composites. Here, the effective dielectric constant of such composite materials depends upon the $\varepsilon$ of the polymer matrix, the $\varepsilon$ of fillers, and the $\varepsilon$ of interfacial layer between filler and the dielectric matrix. To describe such three-phase system, refs. [63,64] introduce a parameter $K$, termed the interfacial volume constant, which accounted for the matrix-filler interaction strength as:

$$
\Phi_{\text {int }}=K \Phi_{N P s} \Phi_{\text {pol }}
$$

where $\Phi_{i n t}, \Phi_{N P_{s}}$, and $\Phi_{\text {pol }}$ are the volume fractions of interfacial phase, dielectric particles, and polymer, respectively. $K$ depends upon the degree of particle clustering.

In the case if dielectric constant of interfacial layer is higher than dielectric constant of polymer matrix and fillers,

$$
K>0, \varepsilon_{\text {interfacial }}>\varepsilon_{\text {polymer }}, \varepsilon_{\text {interfacial }}>\varepsilon_{\text {filler, }}
$$

with increasing of NPs concentration effective dielectric constant of nanocomposite increases, as observed in Figure $4 \mathrm{~b}$.

This model has demonstrated that the dependence of the dielectric constant on NPs concentration is nonmonotonic and can exhibit a maximum as a function of NPs concentration. This maximum appears when there is an overlap of interfacial layers due to NPs agglomeration, thus reducing the interfacial volume fraction that effectively decreases the effective value of dielectric constant of nanocomposite.

In this work, we experimentally fit obtained values of dielectric constant $\varepsilon$ in CS-ZnO NPs films by equations proposed in refs. $[63,64]$ using the Scilab program. The least-squares fitting was performed using standard genetic algorithm optimization functions in the Scilab [65] numerical computational package. The dielectric constant of CS was obtained from measurements on neat CS and $\varepsilon$ of $\mathrm{ZnO}$ was taken 8.5 [27]. Only the values of $K$ and $\varepsilon$ interfacial parameters are the adjustable parameters. 
To convert weight fraction $(\mathrm{Wt})$ to volume fraction $(\mathrm{V})$ of the $\mathrm{ZnO} N \mathrm{Ns}$, the next equation can be used [66]:

$$
V=\frac{W_{t}}{W_{t}+\left(\rho_{Z n O} / \rho_{C S}\left(1-W_{t}\right)\right.}
$$

where, $\rho_{\mathrm{ZnO}}$ and $\rho_{\mathrm{CS}}$ denote the $\mathrm{ZnO}$ and $C S$ density.

The density of CS films is ca. $1.5 \mathrm{~g} \mathrm{~cm}^{-3}[67,68]$, and the true density of $\mathrm{ZnO}$ is $5.6 \mathrm{~g} \mathrm{~cm}^{-3}$ [3].

As a result of optimization, the fitted values are $K=18.3$, and interface dielectric constant equals 69.9. The results of the referred fittings are shown on inset of Figure $4 \mathrm{~b}$ as a continuous line. One can see that this three-phase model fits well the experimental results by predicting a maximum in the dielectric constant. Positive value of $\mathrm{K}$ means that there are significant interfacial interactions between CS and ZnO NPs; these observations were confirmed by FTIR and TGA measurements. Additionally, an interfacial layer dielectric constant value of 69.9 is higher than that of CS and ZnO NPs which is responsible for the observed maximum in Figure $4 \mathrm{~b}$. In summary, the three-phase model is able to capture the correct physics of the nanocomposite by corroborating the behaviors and trends of the experimental measurements.

Similarly, a maximum at $15 \mathrm{wt} . \%$ of $\mathrm{ZnO}$ is observed as in the dependency of Young's modulus on $\mathrm{ZnO}$ concentration (Figure 5). According to refs. [69,70], the Young's modulus in CS films increases with decreasing of water content due to plasticizing effect of water and change in the glass transition temperature. In the TGA measurements water content decreases ca. $5 \%$ in CS-ZnO films with $20 \mathrm{wt} . \%$ of NPs when compared with neat CS. Based upon the results reported in ref. [69,70], this decreasing of water content corresponds to the increasing of Young's modulus approximately to $0.5-1 \mathrm{GPa}$. Therefore, all contributions in elastic module can be related to the change of NPs concentration. Furthermore, a maximum at $15 \mathrm{wt} . \%$ of $\mathrm{ZnO}$ is observed as in the dependency of Young's modulus and dielectric constant on $\mathrm{ZnO}$ concentration (Figures $4 \mathrm{~b}$ and 5). The explanations proposed in the literature on the change of Young's modulus in $\mathrm{ZnO}$ nanocomposites are the following: An additional energy-dissipating mechanism [12], the weakness of intermolecular hydrogen bonding of CS, or the formation of new hydrogen bonding between $\mathrm{CS}$ and $\mathrm{ZnO}$ [15]; these explanations cannot be directly applied to properly address the existence of a maximum in both dielectric and mechanical properties. According to refs. [71-73], the mechanical properties exhibit a similar dependency on the formation of an interfacial layer. Above the percolation threshold, the interfacial regions surrounding the $\mathrm{ZnO}$ NPs overlap indicating percolation in the clusters which dominates in the mechanical properties [72]. Because of the agglomeration of NPs, there is a maximum in both dielectric constant and Young's modulus because further agglomeration of NPs tends to destroy the interfacial regions.

Now let us discuss the dependence of the piezoelectric coefficient on the concentration of NPs. There have been several reports that proposed different models, for instance Refs. [58,74-76] reported an increase of $\mathrm{d}_{33}$ with the volume fraction of the piezoelectric NPs. Moreover, in polymer nanocomposites with NPs with high dielectric constant (such as PZT, BaTiO $3, \mathrm{BZT}$ ) there is an increase of $\mathrm{d}_{33}$ with an increase of the dielectric constant with NPs content [74-76]. However, in $\mathrm{BaTiO}_{3}$-epoxy- $\mathrm{ZnO}$ (with a fixed concentration of $\mathrm{BaTiO}_{3}$ ) [77] and PVDF- $\mathrm{ZnO}$ [56], the dependences of the piezoelectric coefficient and the dielectric constant on the concentration of $\mathrm{ZnO}$ exhibit a maximum (similarly to the maximum presented in Figure $4 \mathrm{~b}$ ). This maximum cannot be explained by classical conductivity percolation effect because the conductivity of CS-ZnO films decreases with ZnO NPs wt.\% (Figure 4a). However, the proposed three-phase model describes well the maximum in dielectric constant (an overlap of interfacial layers due to NPs agglomeration) that effectively decreases the value of dielectric constant and most likely the piezoelectric coefficient. A similar hypothesis on the decreasing of $d_{33}$ due to NPs agglomeration (based on the SEM measurements in $\mathrm{BaTiO}_{3}$-epoxy- $\mathrm{ZnO}$ ) is proposed in ref. [75].

The piezoelectric coefficient $\mathrm{d}_{33}$ in CS-ZnO nanocomposite films with $15 \mathrm{wt} \%$ of NPs $\left(\mathrm{d}_{33}=65.9 \mathrm{pC} / \mathrm{N}\right)$ is higher than most of polymer-ZnO nanocomposites (see Table 1$)$ and it compares with PVDF-PTTE-ZnO nanorods (70.3 $p C / N)$. 
Table 1. Comparison of piezoelectric $\mathrm{d}_{33}$ values in polymer nanocomposites with ZnO NPs.

\begin{tabular}{cccc}
\hline Polymer Nanocomposite & $\begin{array}{c}\text { NPs Dimension } \\
(\mathbf{n m})\end{array}$ & $\begin{array}{c}\mathbf{d}_{33} \\
(p \mathrm{C} / \mathrm{N})\end{array}$ & Refs \\
\hline ZnO, bulk & - & $0.4-12.4$ & {$[53,54]$} \\
\hline photo-epoxy/ZnO films & Less 100 & $15-23$ & {$[78]$} \\
\hline PVDF/ZnO films & $50-80$ & 13.42 & {$[55]$} \\
\hline PVDF/ZnO nanoporous films & $35-45$ & 18.3 & {$[56]$} \\
\hline PVDF $\beta$-phase/ZnO & $50-150$ & 50 & {$[54]$} \\
\hline PVDF-PTTE/ZnO nanorods & - & 70.3 & {$[57]$} \\
\hline PHB/ZnO scaffolds & $80-100$ & 13.7 & {$[79]$} \\
\hline PVDF/ZnO nanorods & - & -1.17 & {$[80]$} \\
\hline CS/ZnO films & 40 & 65.9 & This work \\
\hline Note that PVDF is a polymer with piezoelectric properties. &
\end{tabular}

It is well-known that in classic ferroelectric materials such as $\mathrm{BaTiO}_{3}$, a significant increase in the piezoelectric coefficient in materials with nanodomain structure was observed. The value of $d_{33}$ in samples with grains $50 \mathrm{~nm}$ increases more than twice to $416 \mathrm{pC} / \mathrm{N}$ [81] compared with grains of $500 \mathrm{~nm}$ ( $200 \mathrm{pC} / \mathrm{N})$. In the case of the $\mathrm{ZnO} N \mathrm{Ns}$ with dimension ca. $40 \mathrm{~nm}$ the size of the nanodomains must be less than $40 \mathrm{~nm}$ that can increase $d_{33}$ in CS-ZnO nanocomposite. Furthermore, high value of $d_{33}$ in CS-ZnO nanocomposite films can be related to their elastic properties that play an important role in the piezoelectric performance of piezoelectric polymer composites [58]. Additionally, refs. [82,83] reported that CS films with $91.2 \%$ of deacetylation degree exhibit a piezoelectric coefficient $\mathrm{d}_{33}$ between 7 and 18.4 $p C / N$. These piezoelectric properties are observed because of the fact that crystalline part of CS has non-centrosymmetry orthorhombic structure with piezoelectric properties [82]. However, in our work we did not observe piezoelectric properties of neat CS films; this observation may be traceable to the lower deacetylation degree of CS ( $c a .72 \%)$. Nevertheless, in the presence of an electrical field (at which we measured $d_{33}$ ) an alignment of CS chains can be observed. The alignment of CS chains can be correlated with the increase in dielectric and piezoelectric properties of the composites [84]. Therefore, the high $\mathrm{d}_{33}$ in CS/ZnO films can be traced to the synergistic effect of nanodomain structure of NPs, piezoelectricity of CS, elastic properties of films, and optimum NPs concentration.

\section{Conclusions}

The investigation of CS-ZnO films with different wt.\% of NPs shows that a maximum value is observed in both dielectric constant and Young's modulus. Similarly, at the same concentration of NPs there appears the highest value of the piezoelectric coefficient. This maximum can be related to cluster agglomeration of $\mathrm{ZnO} N P s$ above the dielectric and mechanical percolation threshold (15 wt.\% of ZnO NPs). These properties of nanocomposite's films are interpreted by using a three-phase model which includes: (1) CS matrix, (2) ZnO NPs, and (3) interfacial layer between $\mathrm{ZnO}$ and CS matrix. This interface layer is responsible for the higher dielectric constant when compared with the $\varepsilon$ of neat $\mathrm{CS}$ and $\mathrm{ZnO}$, a higher Young's modulus, and a higher $\mathrm{d}_{33}$. The piezoelectric coefficient $\mathrm{d}_{33}$ in CS-ZnO nanocomposite films with $15 \mathrm{wt}$. \% of NPs $\left(\mathrm{d}_{33}=65.9 \mathrm{pC} / \mathrm{N}\right)$ is higher than in the most of polymer-ZnO nanocomposites because of the synergistic effect of nanodomain structure of NPs, piezoelectricity of CS, elastic properties of CS, and optimum NPs concentration.

Based upon the presented methodology, one can try to fine-tune the desired properties by manipulating the concentration and agglomeration of NPs that ultimately control the molecular interactions. It is noteworthy that these variables not only depend upon the dimension of NPs but also on the method of preparation and the chemistry of constituents. However, the methodology presented here allows to determine the direct relationship between dielectric, mechanical, piezoelectrical 
properties, and the concentration of nanoparticles that may prove useful in the design and optimization of polymer-based nanocomposites for different applications.

In summary, the molecular understanding of nanoscale properties of CS-ZnO nanocomposites is relevant in the development of biocompatible sensors, actuators, nanogenerators, etc. for flexible electronics, and biomedical applications.

Author Contributions: Conceptualization, methodology, investigation, writing-original draft preparation E.P.; writing-investigation, discussion, review, and editing G.L.-B.; investigation J.M.Y.L.; investigation A.G.S.; software Y.K. All authors have read and agreed to the published version of the manuscript.

Funding: This research was funded and supported by CONACYT, Mexico (grant A1-S-9557).

Acknowledgments: The authors are grateful to J.A. Muñoz Salas for technical assistance in electrical measurements, R.A. Mauricio-Sánchez for assistance in FTIR measurements, M.A. Hernandez Landaverde for assistance in XRD measurements, and R. Flores Farias for assistance in piezoelectric measurements.

Conflicts of Interest: The authors declare no conflict of interest.

\section{References}

1. Kalpana, V.N.; Rajeswari, V.D. A Review on Green Synthesis, Biomedical Applications, and Toxicity Studies of ZnO NPs. Bioinorg. Chem. Appl. 2018, 2018, 3569758. [CrossRef] [PubMed]

2. Mishra, Y.K.; Adelung, R. ZnO tetrapod materials for functional applications. Mater. Today 2018, 21, 631-651. [CrossRef]

3. Klingshirn, C. ZnO: Material, Physics and Applications. Chem. Phys. Chem. 2007, 8, 782-803. [CrossRef] [PubMed]

4. Selvaraj, T.; Perumal, V.; Khor, S.F.; Anthony, L.S.; Gopinath, S.C.B.; Mohamed, N.M. The recent development of polysaccharides biomaterials and their performance for supercapacitor applications. Mater. Res. Bull. 2020, 126, 110839. [CrossRef]

5. Jin, C.; Hao, N.; Xu, Z.; Trase, I.; Nie, Y.; Dong, L.; Closson, A.; Chen, Z.; Zhang, J.X.J. Flexible piezoelectric nanogenerators using metal-doped ZnO-PVDF films. Sens. Actuators A Phys. 2020, 305, 111912. [CrossRef]

6. Fakhri, P.; Amini, B.; Bagherzadeh, R.; Kashfi, M.; Latifi, M.; Yavari, N.; Kani, S.A.; Kong, L. Flexible hybrid structure piezoelectric nanogenerator based on $\mathrm{ZnO}$ nanorod/PVDF nanofibers with improved output. RSC Adv. 2019, 9, 10117. [CrossRef]

7. Sinar, D.; Knopf, G.K. Disposable piezoelectric vibration sensors with PDMS/ZnO transducers on printed graphene-cellulose electrodes. Sens. Actuators A Phys. 2020, 302, 111800. [CrossRef]

8. Buzarovska, A.; Dinescu, S.; Lazar, A.D.; Serban, M.; Pircalabioru, G.G.; Costache, M.; Gualandi, C.; Averous, L. Nanocomposite foams based on flexible biobased thermoplastic polyurethane and $\mathrm{ZnO}$ nanoparticles as potential wound dressing materials. Mater. Sci. Eng. C 2019, 104, 109893. [CrossRef]

9. Choudhary, S. Structural, optical, dielectric and electrical properties of (PEO-PVP)-ZnO nanocomposites. J. Phys. Chem. Solids 2018, 121, 196-209. [CrossRef]

10. Carvalho, J.T.; Dubceac, V.; Grey, P.; Cunha, I.; Fortunato, E.; Martins, R.; Clausner, A.; Zschech, E.; Pereira, L. Fully Printed Zinc Oxide Electrolyte-Gated Transistors on Paper. Nanomaterials 2019, 9, 169. [CrossRef]

11. Souza, V.G.L.; Rodrigues, C.; Valente, S.; Pimenta, C.; Pires, J.R.A.; Alves, M.M.; Santos, C.F.I.; Coelhoso, M.; Fernando, A.L. Eco-Friendly ZnO/Chitosan Bionanocomposites Films for Packaging of Fresh Poultry Meat. Coatings 2020, 10, 110. [CrossRef]

12. Ridwan, R.; Rihayat, T.; Suryani, S.; Ismi, A.S.; Nurhanifa, N.; Riskina, S. Combination of poly lactid acid zinc oxide nanocomposite for antimicrobial packaging application. IOP Conf. Ser. Mater. Sci. Eng. 2020, 830, 042018. [CrossRef]

13. Rodrigues, C.; De Mello, J.M.M.; Dalcanton, F.; Macuvele, D.L.P.; Padoin, N.; Fiori, M.A.; Soares, C.; Riella, H.G. Mechanical, Thermal and Antimicrobial Properties of Chitosan-Based-Nanocomposite with Potential Applications for Food Packaging. J. Polym. Environ. 2020, 28, 1216-1236. [CrossRef]

14. Vaseeharan, B.; Sivakamavalli, J.; Thaya, R. Synthesis and characterization of chitosan-ZnO composite and its antibiofilm activity against aquatic bacteria. J. Compos. Mater. 2013, 49, 177-184. [CrossRef]

15. Li, L.-H.; Deng, J.-C.; Deng, H.-R.; Liu, Z.-L.; Xin, L. Synthesis and characterization of chitosan/ZnO nanoparticle composite membranes. Carbohydr. Res. 2010, 345, 994-998. [CrossRef] [PubMed] 
16. Anandhavelu, S.; Dhanasekaran, V.; Sethuraman, V.; Park, H.J. Chitin and Chitosan Based Hybrid Nanocomposites for Super Capacitor Applications. J. Nanosci. Nanotechnol. 2017, 17, 1321-1328. [CrossRef]

17. Qiu, B.; Xu, X.-F.; Deng, R.-H.; Xia, G.-Q.; Shang, X.-F.; Zhou, P.-H. Construction of chitosan/ZnO nanocomposite film by in situ precipitation. Int. J. Biol. Macromol. 2019, 122, 82-87. [CrossRef]

18. Abarna, B.; Preethi, T.; Rajarajeswari, G.R. Single-pot solid-state synthesis of ZnO/chitosan composite for photocatalytic and antitumour applications. J. Mater. Sci. Mater. Electron. 2019, 30, 21355-21368. [CrossRef]

19. Rahman, M.; Muraleedaran, P.K.; Mujeeb, V.M.A. Applications of chitosan powder with in situ synthesized nano $\mathrm{ZnO}$ particles as an antimicrobial agent. Int. J. Biol. Macromol. 2015, 77, 266-272. [CrossRef]

20. Jayasuriya, A.C.; Aryaei, A.; Jayatissa, A.H. ZnO nanoparticles induced effects on nanomechanical behavior and cell viability of chitosan films. Mater. Sci. Eng. C 2013, 33, 3688-3696. [CrossRef]

21. Das, K.; Maiti, S.; Liu, D. Morphological, Mechanical and Thermal Study of ZnO Nanoparticle Reinforced Chitosan Based Transparent Biocomposite Films. J. Inst. Eng. (India) Ser. D 2014, 95, 35-41. [CrossRef]

22. Ummartyotin, S.; Pechyen, C. Physico-Chemical Properties of $\mathrm{ZnO}$ and Chitosan Composite for Packaging Material. J. Biobased Mater. Bioenergy 2017, 11, 183-192. [CrossRef]

23. Rahman, P.M.; Mujeeb, V.M.A.; Muraleedharan, K.; Thomas, S.K. Chitosan/nano ZnO composite films: Enhanced mechanical, antimicrobial and dielectric properties. Arab. J. Chem. 2018, 11, 120-127. [CrossRef]

24. Indumathi, M.P.; Sarojini, K.S.; Rajarajeswari, G.R. Antimicrobial and biodegradable chitosan/cellulose acetate phthalate/ZnO nano composite films with optimal oxygen permeability and hydrophobicity for extending the shelf life of black grape fruits. Int. J. Biol. Macromol. 2019, 132, 1112-1120. [CrossRef]

25. Hezma, A.M.; Rajeh, A.; Mannaa, M.A. An insight into the effect of zinc oxide nanoparticles on the structural, thermal, mechanical properties and antimicrobial activity of Cs/PVA composite. Colloids Surf. A Physicochem. Eng. Asp. 2019, 581, 123821. [CrossRef]

26. Alturki, A.M. Effect of Preparation Method on the Particles Size, Dielectric Constant and Antibacterial Properties of $\mathrm{ZnO}$ Nanoparticles and Thin Film of ZnO/Chitosan. Orient. J. Chem. 2018, 34, 548-554. [CrossRef]

27. Warlimont, H.; Martienssen, W. (Eds.) Springer Handbook of Materials Data; Springer Nature: Cham, Switzerland, 2018.

28. Swaroop, K.; Naveen, C.S.; Jayanna, H.S.; Somashekarappa, H.M. Effect of gamma irradiation on DC electrical conductivity of $\mathrm{ZnO}$ nanoparticles. In AIP Conference Proceedings; AIP Publishing LLC: Melville, NY, USA, 2015; Volume 1665, p. 050100. [CrossRef]

29. Naveen, C.S.; Jayanna, H.S.; Lamani, A.R.; Rajeeva, M.P. Temperature dependent DC electrical conductivity studies of ZnO nanoparticle thick films prepared by simple solution combustion method. In AIP Conference Proceedings; AIP Publishing LLC: Melville, NY, USA, 2014.

30. Wang, R.S.; An, J.; Ong, H. Studies of Interfacial Optical and Electrical Properties on Transparent Dielectrics/ZnO Systems; Cambridge University Press (CUP): Cambridge, UK, 2006; Volume 928, pp. 35-78.

31. Wang, G.-S.; Wu, Y.-Y.; Zhang, X.; Li, Y.; Guo, L.; Cao, M. Controllable synthesis of uniform ZnO nanorods and their enhanced dielectric and absorption properties. J. Mater. Chem. A 2014, 2, 8644-8651. [CrossRef]

32. Wang, G.; Deng, Y.; Xiang, Y.; Guo, L. Fabrication of radial ZnO nanowire clusters and radial ZnO/PVDF composites with enhanced dielectric properties. Adv. Funct. Mater. 2008, 18, 2584-2592. [CrossRef]

33. Rajesh, K.; Crasta, V.; Kumar, N.B.R.; Shetty, G. Effect of ZnO nanofiller on dielectric and mechanical properties of PVA/PVP blend. In AIP Conference Proceedings; AIP Publishing LLC: Melville, NY, USA, 2019; Volume 2162, p. 020096.

34. Wang, G.; Deng, Y.; Guo, L. Single-Crystalline ZnO Nanowire Bundles: Synthesis, Mechanism and Their Application in Dielectric Composites. Chem. A Eur. J. 2010, 16, 10220-10225. [CrossRef]

35. Hemalatha, K.S.; Rukmani, K. Concentration dependent dielectric, AC conductivity and sensing study of ZnO-polyvinyl alcohol nanocomposite films. Int. J. Nanotechnol. 2017, 14, 961-974. [CrossRef]

36. Efros, A.L.; Shklovskii, B.I. Critical Behaviour of Conductivity and Dielectric Constant near the Metal-Non-Metal Transition Threshold. Phys. Status Solidi (B) 1976, 76, 475-485. [CrossRef]

37. Bergman, D.J.; Stroud, D. Physical Properties of Macroscopically Inhomogeneous Media. Methods Exp. Phys. 1992, 46, 147-269. [CrossRef]

38. Díez-Pascual, A.M.; Díez-Vicente, A.L. ZnO-Reinforced Poly(3-hydroxybutyrate-co-3-hydroxyvalerate) Bionanocomposites with Antimicrobial Function for Food Packaging. ACS Appl. Mater. Interfaces 2014, 6, 9822-9834. [CrossRef] [PubMed] 
39. Diez-Pascual, A.M.; Xu, C.; Luque, R. Development and characterization of novel poly(ether ether ketone)/ZnO bionanocomposites. J. Mater. Chem. B 2014, 2, 3065. [CrossRef]

40. Poddar, M.K.; Sharma, S.; Moholkar, V.S. Investigations in two-step ultrasonic synthesis of PMMA/ZnO nanocomposites by in-situ emulsion polymerization. Polymer 2016, 99, 453-469. [CrossRef]

41. Pantani, R.; Gorrasi, G.; Vigliotta, G.; Murariu, M.; Dubois, P. PLA-ZnO nanocomposite films: Water vapor barrier properties and specific end-use characteristics. Eur. Polym. J. 2013, 49, 3471-3482. [CrossRef]

42. Abbas, M.; Buntinx, M.; Deferme, W.; Peeters, R. (Bio)polymer/ZnO Nanocomposites for Packaging Applications: A Review of Gas Barrier and Mechanical Properties. Nanomaterials 2019, 9, 1494. [CrossRef]

43. Díez-Pascual, A.M.; Díez-Vicente, A.L. High-Performance Aminated Poly(phenylene sulfide)/ZnO Nanocomposites for Medical Applications. ACS Appl. Mater. Interfaces 2014, 6, 10132-10145. [CrossRef]

44. AboMostafa, H.M.; El Komy, G.M. Enhancement of Structural, Dielectric and Mechanical Properties of Ps: Fe Doped ZnO Based Polymer Nanocomposites. J. Inorg. Organomet. Polym. Mater. 2019, 29, $908-916$. [CrossRef]

45. Kumar-Krishnan, S.; Prokhorov, E.; Ramirez-Cardona, M.; Hernández-Landaverde, M.A.; Zárate-Triviño, D.G.; Kovalenko, Y.; Sanchez, I.C.; Mendez-Nonell, J.; Bárcenas, G.L. Novel gigahertz frequency dielectric relaxations in chitosan films. Soft Matter 2014, 10, 8673-8684. [CrossRef]

46. Abdelhady, M.M. Preparation and Characterization of Chitosan/Zinc Oxide Nanoparticles for Imparting Antimicrobial and UV Protection to Cotton Fabric. Int. J. Carbohydr. Chem. 2012, 2012, 1-6. [CrossRef]

47. González-Campos, J.; Prokhorov, E.; Bárcenas, G.; Sanchez, I.C.; Lara-Romero, J.; Mendoza-Duarte, M.E.; Villaseñor, F.; Guevara-Olvera, L. Chitosan/silver nanoparticles composite: Molecular relaxations investigation by dynamic mechanical analysis and impedance spectroscopy. J. Polym. Sci. Part B Polym. Phys. 2010, 48, 739-748. [CrossRef]

48. Corazzari, I.; Nisticò, R.; Turci, F.; Faga, M.G.; Franzoso, F.; Tabasso, S.; Magnacca, G. Advanced physico-chemical characterization of chitosan by means of TGA coupled on-line with FTIR and GCMS: Thermal degradation and water adsorption capacity. Polym. Degrad. Stab. 2015, 112, 1-9. [CrossRef]

49. Panomsuwan, G.; Manuspiya, H. A comparative study of dielectric and ferroelectric properties of sol-gel-derived BaTiO3 bulk ceramics with fine and coarse grains. Appl. Phys. A 2018, 124, 713. [CrossRef]

50. Prokhorov, E.; Luna-Bárcenas, G.; González-Campos, J.B.; Kovalenko, Y.; García-Carvajal, Z.Y.; Mota-Morales, J. Proton conductivity and relaxation properties of chitosan-acetate films. Electrochim. Acta 2016, 215, 600-608. [CrossRef]

51. Vyshatko, N.P.; Brioso, P.M.; De La Cruz, J.P.; Vilarinho, P.M.; Kholkin, A.L. Fiber-optic based method for the measurements of electric-field induced displacements in ferroelectric materials. Rev. Sci. Instrum. 2005, 76, 85101. [CrossRef]

52. Fialka, J. Determination of the Piezoelectric Charge Constant D33 Measured by the Laser Interferometer and Frequency Method. In Annals of DAAAM for 2010 E Proceedings of the 21st International DAAAM Symposium; DAAAM International: Vienna, Austria, 2010; Volume 21.

53. Sinha, N.; Ray, G.; Bhandari, S.; Godara, S.; Kumar, B. Synthesis and enhanced properties of cerium doped ZnO nanorods. Ceram. Int. 2014, 40, 12337-12342. [CrossRef]

54. Thakur, P.; Kool, A.; Hoque, N.A.; Bagchi, B.; Khatun, F.; Biswas, P.; Brahma, D.; Roy, S.; Banerjee, S.; Das, S. Superior performances of in situ synthesized ZnO/PVDF thin film based self-poled piezoelectric nanogenerator and self-charged photo-power bank with high durability. Nano Energy 2018, 44, 456-467. [CrossRef]

55. Satthiyaraju, M.; Ramesh, T. Nanomechanical, Mechanical Responses and Characterization of Piezoelectric Nanoparticle-Modified Electrospun PVDF Nanofibrous Films. Arab. J. Sci. Eng. 2019, 44, 5697-5709. [CrossRef]

56. Zhao, P.; Wang, S.; Kadlec, A. Piezoelectric and dielectric properties of nanoporous polyvinylidence fluoride (PVDF) films. Behav. Mech. Multifunct. Mater. Compos. 2016 2016, 9800, 98000. [CrossRef]

57. Singh, H.H.; Khare, N. Flexible ZnO-PVDF/PTFE based piezo-tribo hybrid nanogenerator. Nano Energy 2018, 51, 216-222. [CrossRef]

58. Li, J.; Zhu, Z.; Fang, L.; Guo, S.; Erturun, U.; Zhu, Z.; West, J.E.; Ghosh, S.; Kang, S.H. Analytical, numerical, and experimental studies of viscoelastic effects on the performance of soft piezoelectric nanocomposites. Nanoscale 2017, 9, 14215-14228. [CrossRef] 
59. Godavarti, U.; Mote, V.; Dasari, M. Role of cobalt doping on the electrical conductivity of ZnO nanoparticles. J. Asian Ceram. Soc. 2017, 5, 391-396. [CrossRef]

60. Barber, P.; Balasubramanian, S.; Anguchamy, Y.; Gong, S.; Wibowo, A.; Gao, H.; Ploehn, H.J.; Loye, H.-C. Polymer Composite and Nanocomposite Dielectric Materials for Pulse Power Energy Storage. Materials 2009, 2, 1697-1733. [CrossRef]

61. Kirkpatrick, S. Percolation and Conduction. Rev. Mod. Phys. 1973, 45, 574-588. [CrossRef]

62. Cai, W.-Z.; Tu, S.-T.; Gong, J.-M. A Physically Based Percolation Model of the Effective Electrical Conductivity of Particle Filled Composites. J. Compos. Mater. 2006, 40, 2131-2142. [CrossRef]

63. Vo, H.T.; Shi, F.G. Towards model-based engineering of optoelectronic packaging materials: Dielectric constant modeling. Microelectron. J. 2002, 33, 409-415. [CrossRef]

64. Todd, M.G.; Shi, F.G. Characterizing the interphase dielectric constant of polymer composite materials: Effect of chemical coupling agents. J. Appl. Phys. 2003, 94, 4551. [CrossRef]

65. Campbell, S.L.; Chancelier, J.P.; Nikoukhah, R. Modeling and Simulation in Scilab/Scicos with ScicosLab 4.4; Springer: New York, NY, USA, 2010.

66. Zakaria, A.Z.; Shelesh-Nezhad, K. The effects of interphase and interface haracteristics on the tensile behaviour of POM/CaCO3 nanocomposites. Nanomater. Nanotechnol. 2004, 17, 1-10.

67. Nunthanid, J.; Laungtana-Anan, M.; Sriamornsak, P.; Limmatvapirat, S.; Puttipipatkhachorn, S.; Lim, L.-Y.; Khor, E. Characterization of chitosan acetate as a binder for sustained release tablets. J. Control. Release 2004, 99, 15-26. [CrossRef] [PubMed]

68. Mezina, E.A.; Lipatova, I.M.; Losev, N.V. Effect of mechanical activation on rheological and film-forming properties of suspensions of barium sulfate in chitosan solutions. Russ. J. Appl. Chem. 2011, 84, 486-490. [CrossRef]

69. Aguirre-Loredo, R.Y.; Hernández, A.I.R.; Morales-Sánchez, E.; Gómez-Aldapa, C.A.; Velazquez, G. Effect of equilibrium moisture content on barrier, mechanical and thermal properties of chitosan films. Food Chem. 2016, 196, 560-566. [CrossRef] [PubMed]

70. Cazón, P.; Vázquez, M.; Velazquez, G. Environmentally Friendly Films Combining Bacterial Cellulose, Chitosan, and Polyvinyl Alcohol: Effect of Water Activity on Barrier, Mechanical, and Optical Properties. Biomacromolecules 2019, 21, 753-760. [CrossRef] [PubMed]

71. Baxter, S.C.; Burrows, B.J.; Fralick, B.S. Mechanical percolation in nanocomposites: Microstructure and micromechanics. Probabilistic Eng. Mech. 2016, 44, 35-42. [CrossRef]

72. Padmanabhan, V. Percolation of high-density polymer regions in nanocomposites: The underlying property for mechanical reinforcement. J. Chem. Phys. 2013, 139, 144904. [CrossRef]

73. Fralick, B.S.; Gatzke, E.P.; Baxter, S.C. Three-dimensional evolution of mechanical percolation in nanocomposites with random microstructures. Probabilistic Eng. Mech. 2012, 30, 1-8. [CrossRef]

74. Hua, Z.; Shi, X.; Chen, Y. Preparation, Structure, and Property of Highly Filled Polyamide 11/BaTiO3 Piezoelectric Composites Prepared Through Solid-State Mechanochemical Method. Polym. Compos. 2017, 40, E177-E185. [CrossRef]

75. Choudhury, A. Dielectric and piezoelectric properties of polyetherimide/BaTiO3 nanocomposites. Mater. Chem. Phys. 2010, 121, 280-285. [CrossRef]

76. Hemeda, O.M.; Tawfik, A.; El-Shahawy, M.M.; Darwish, K.A. Enhancement of piezoelectric properties for [poly(vinylidene fluoride)/barium zirconate titanate] nanocomposites. Eur. Phys. J. Plus. 2017, 132, 333. [CrossRef]

77. Tuff, W.; Manghera, P.; Tilghman, J.; Van Fossen, E.; Chowdhury, S.; Ahmed, S.; Banerjee, S. BaTiO3-Epoxy-ZnO-Based Multifunctional Composites: Variation in Electron Transport Properties due to the Interaction of ZnO Nanoparticles with the Composite Microstructure. J. Electron. Mater. 2019, 48, 4987-4996. [CrossRef]

78. Kandpal, M.M.; Sharan, C.; Poddar, P.; Prashanthi, K.; Apte, R.; Rao, V.R. Photopatternable nano-composite (SU-8/ZnO) thin films for piezo-electric applications. Appl. Phys. Lett. 2012, 101, 104102. [CrossRef]

79. Zviagin, A.S.; Chernozem, R.V.; Surmeneva, M.A.; Pyeon, M.; Frank, M.; Ludwig, T.; Tutacz, P.; Ivanov, Y.F.; Mathur, S.; Surmeneva, M.A. Enhanced piezoelectric response of hybrid biodegradable 3D poly(3-hydroxybutyrate) scaffolds coated with hydrothermally deposited $\mathrm{ZnO}$ for biomedical applications. Eur. Polym. J. 2019, 117, 272-279. [CrossRef] 
80. Singh, H.H.; Singh, S.; Khare, N. Enhanced $\beta$-phase in PVDF polymer nanocomposite and its application for nanogenerator. Polym. Adv. Technol. 2017, 29, 143-150. [CrossRef]

81. Shen, Z.-Y.; Li, J.-F. Enhancement of piezoelectric constant d33 in BaTiO3 ceramics due to nano-domain structure. J. Ceram. Soc. Jpn. 2010, 118, 940-943. [CrossRef]

82. Praveen, E.; Murugan, S.; Jayakumar, K. Investigations on the existence of piezoelectric property of a bio-polymer-Chitosan and its application in vibration sensors. RSC Adv. 2017, 7, 35490-35495. [CrossRef]

83. Hänninen, A.; Sarlin, E.; Lyyra, I.; Salpavaara, T.; Kellomäki, M.; Tuukkanen, S. Nanocellulose and chitosan based films as low cost, green piezoelectric materials. Carbohydr. Polym. 2018, 202, 418-424. [CrossRef]

84. Van den Ende, D.A.; Bory, B.F.; Groen, W.A.; Van der Zwaag, S. Improving the d33 and g33 properties of 0-3 piezoelectric composites by Dielectrophoresis. J. Appl. Phys. 2010, 107, 024107. [CrossRef]

2020 by the authors. Licensee MDPI, Basel, Switzerland. This article is an open access article distributed under the terms and conditions of the Creative Commons Attribution (CC BY) license (http://creativecommons.org/licenses/by/4.0/). 